\title{
The Plant Extract Collection Kiel in Schleswig-Holstein (PECKISH) Is an Open Access Screening Library
}

\author{
Simone Onur ${ }^{1}$, Heiko Stöckmann ${ }^{2}$, Marion Zenthoefer ${ }^{3}$, Levent Piker ${ }^{3} \&$ Frank Döring $^{1}$ \\ ${ }^{1}$ Department of Molecular Prevention, Kiel University, Kiel, Germany \\ ${ }^{2}$ ACT Foods GmbH, Bad Fallingbostel, Germany \\ ${ }^{3}$ CRM - Coastal Research \& Management, Kiel, Germany \\ Correspondence: Frank Döring, Department of Molecular Prevention, Institute of Human Nutrition and Food \\ Science, Kiel University, Heinrich-Hecht-Platz 10, 24118 Kiel, Germany. Tel: 49-431-880-5657. E-mail: \\ sek@molprev.uni-kiel.de
}

Received: May 21, 2013 Accepted: June 25, 2013 Online Published: July 24, 2013

doi:10.5539/jfr.v2n4p101 URL: http://dx.doi.org/10.5539/jfr.v2n4p101

\begin{abstract}
Because plants and their extracts are a potent resource for bioactive substances we developed the plant extract collection Kiel in Schleswig-Holstein (PECKISH) as an open access screening library. PECKISH contains more than 4500 unique aqueous (about 64\%), ethanolic (about 32\%), and other (about 4\%) extracts from $>880$ different plant species and 11 different plant tissues. PECKISH represents about 190 plant families. Extracts were obtained from health shops, outdoor cultivated plants, marine algae, herbs from traditional Chinese medicine, African plants and known medicinal plants. Concentrated and sterilized extracts are stored at $-80^{\circ} \mathrm{C}$ and are available in a 96 -well plate format including empty wells for positive and negative controls. The library format allows medium throughput screenings using enzymatic assays, cell-based assays or phenotypic read-outs using model-organisms such as C. elegans or D. melanogaster. Screenings based on PECKISH are useful to develop dietary supplements, functional foods or drugs. The uniqueness of PECKISH lies in its broad diversity of plant extracts and its open access character.
\end{abstract}

Keywords: plant extract collection, biomedical screening, research library, biomedical research

\section{Introduction}

Plants and their extracts contain a large number of bioactive substances. For example, saponins with anti-oxidative capacity, capsaicin with anti-obesic effects, and fucosterols with anti-carcinogenic properties were identified in soybeans, red pepper, and Wakame, respectively (Arai, 1996). Due to their anti-inflammatory activities, plants used in the traditional Chinese medicine (TCM) are able to reduce the progress of atherosclerosis (Gupta, Singhal, Goyle, \& Sharma, 2001; Subramaniam et al., 2011). Similar effects are shown to be shared by marine plants such as seaweeds or algae (Khan et al., 2008; Yang et al., 2011). More recently, plant extracts were subject to extensive epigenetics (Kirk, Cefalu, Ribnicky, Liu, \& Eilertsen, 2008; Liu et al., 2001), endocrinology (Liu et al., 2001), inflammatory medicine (Kahkonen et al., 1999), and nutrigenomics (Eggenschwiler et al., 2006; Koch \& Malek, 2011) studies. This stresses plants and their extracts as having wide-ranging health effects and renders them useful in biomedical research.

During the last years, synthetic and semi-synthetic natural libraries as well as pure compound libraries were established by pharmaceutical companies and by research groups (Bindseil et al., 2001; de Morais Lima et al., 2011; Eisenberg et al., 2011). Within the framework of the Developmental Therapeutics Program (DTP) of the U.S. National Cancer Institute, a screening library containing more than 230,000 unique extracts from plants, marine organisms, and microbes was established (McCloud, 2010). All of these libraries are not publicly available and were essentially established for drug development. Other extract collections based on Asian plants (Buehrer et al., 2012; Eisenberg et al., 2011), marine plants (Khan et al., 2008), plants with high amounts of special substances (Kahkonen et al., 1999), plants with specific effects or substances (Kahkonen et al., 1999; Kirk et al., 2008) and small libraries with less than 40 different extracts (Khan et al., 2008; Pun et al., 2010) were described previously. These libraries are also not accessible and contain extracts from a limited number of plant families. Here we report establishment of the plant extract collection Kiel in Schleswig-Holstein (PECKISH) as an open access screening 
library, containing a broad diversity of plant extracts as a useful resource for the development of dietary supplements, functional foods, or drugs. Since there is evidence that plant specimen of about 20 years of age still contain biological active compounds (Klausmeyer et al., 2009), we anticipate that our library will be useful as a long-term resource for screening of bioactive compounds.

\section{Materials and Methods}

\subsection{Collection and Handling of Plant Material}

The plant material was purchased from various local herbal suppliers, as well as from suppliers from Northern Europe (e.g. Germany, Netherlands, or Austria) and several from Western Africa (Cameroon). Several special local plants were cultivated outdoor in Northern Germany especially for PECKISH. The algae were collected by Coastal Research \& Management (CRM), Kiel, Germany at different coasts in Europe (e.g. Denmark, France), delivered from Japanese suppliers and/or cultivated at the local coast of Kiel, Germany. For preservation, the algae raw material was either dried or frozen at $-20{ }^{\circ} \mathrm{C}$. In all other cases, raw material was dried when delivered. The plant material included berries, flesh and fruits, vegetables, corms, cereals, glumes, herbs, plant sprouts, hulls, seeds, leaves and bark, boughs, woods, roots, bulbs, blossoms (with and without calyx), petals, buds, grasses, needles, corns, barbs, parings, pods and pits, gum resin, nuts, mushrooms, cones, and thalli. Before and after extraction, the raw plant material was kept in wooden boxes at room temperature, each packed in its original bag. 2.2 Extraction Procedures

42 extracts were obtained from Plantextrakt GmbH \& Co. KG (Vestenbergsgreuth, Germany) in a dried condition. 63 extracts were delivered by Flavex Naturextrakte GmbH (Rehlingen, Germany) as fluids and 41 extracts were produced by Caesar \& Loretz GmbH (Hilden, Germany) as so-called 'tea-drugs'. The dried extracts from Plantextrakt $\mathrm{GmbH} \& \mathrm{Co} \mathrm{KG}$ were dissolved in double distilled water. 128 aqueous extracts from frozen and air dried algae as well as 27 acetonical extracts from air dried algae were provided by CRM, Kiel, Germany. More than $90 \%$ of the extracts were produced by aqueous extraction, ethanolic extraction or by producing a concentrated infusion (Figure 1). In most cases, the herb-to-solvent ratio was 1:10. The final concentration of extracts was about $5-10 \mathrm{mg} / \mathrm{ml}$ for aqueous and $1-5 \mathrm{mg} / \mathrm{ml}$ for ethanolic extracts. For aqueous and ethanolic extraction, the air dried plants were grinded by IKA analytical mill (Type A11 basic) and weighted ( $3 \mathrm{~g}$ ) into a test tube. A total of $30 \mathrm{ml}$ of boiling double distilled water or ethanol (Rotipuran $\geq 99.8 \%$ p.a., Roth, Germany) was added. The suspension of solvent and powdered plant material was stirred slightly. Tubes were sonicated (Bandelin Sonoplus UW 2070) for 1 minute and centrifuged (Eppendorf Centrifuge 5702) for 2 minutes (2.000 g), respectively. The supernatant was cleaned from the plant material via folded filter (Macherey-Nagel MN $615^{1 / 4}, 185 \mathrm{~mm}$ ). The extracts were initially stored in $15 \mathrm{ml}$ tubes (Sarstedt, Germany) and frozen by $-80{ }^{\circ} \mathrm{C}$ immediately after having finished the extraction procedure. To produce a concentrated infusion, the whole raw material $(10 \mathrm{~g})$ was soused with $100 \mathrm{ml}$ of boiling double distilled water, slightly stirred, and steeped for 10 minutes. After this, the solution was filtered by a folded filter (Macherey-Nagel MN 615 1/4, $185 \mathrm{~mm}$ ) into a $15 \mathrm{ml}$ tube and initially frozen by $-80^{\circ} \mathrm{C}$.

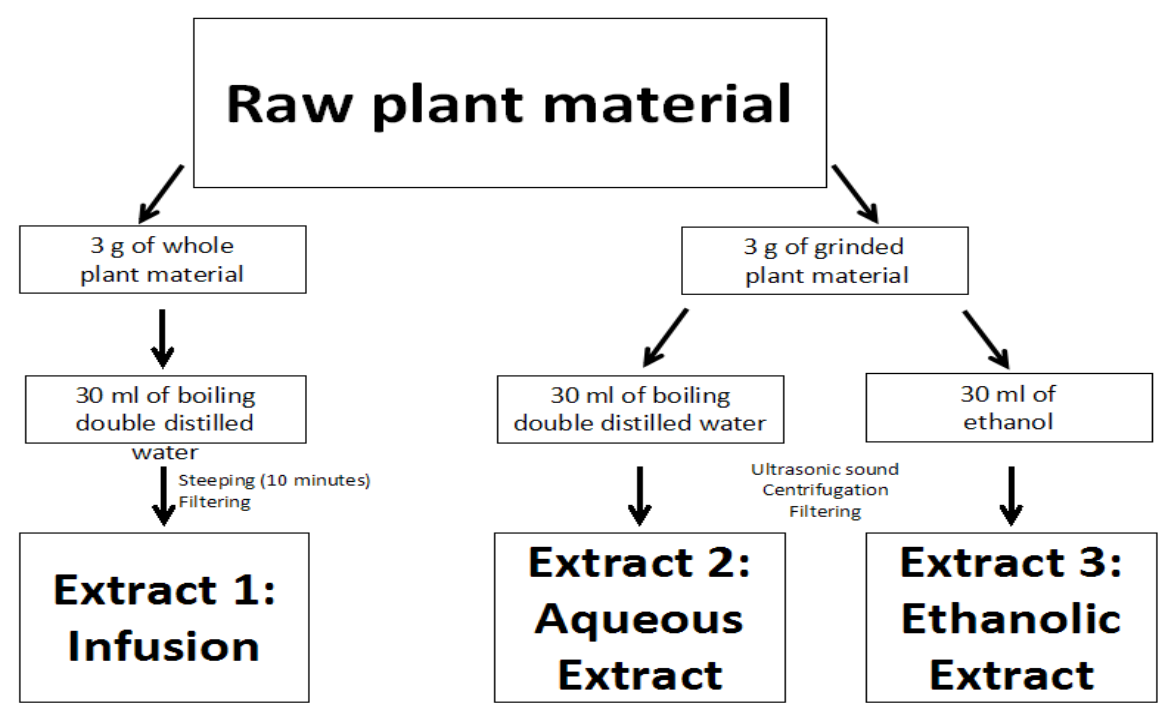

Figure 1. Extraction protocol of extracts within PECKISH 


\subsection{Storage of Extract Aliquots}

Plant extracts were aliquoted $(1800 \mu \mathrm{l})$ with a multi-pipette (Pipet-Lite ${ }^{\mathrm{TM}}$ XLS Adjustable Spacer, Mettler Toledo,

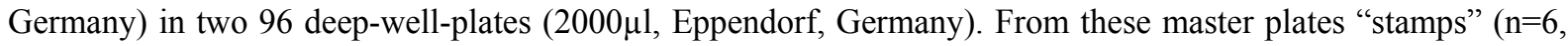
$150 \mu \mathrm{l})$ were made in conventional 96 well-plates with the same multi-pipette. All plates were covered by an adhesive storage foil (Eppendorf, Germany). Afterwards, master plates as well as stamps were re-frosted and stored in different $-80{ }^{\circ} \mathrm{C}$ freezers, respectively. The retained samples were kept in their origin tubes by $-20{ }^{\circ} \mathrm{C}$. The whole library was sterilized by gamma radiation (BGS Beta-Gamma-Service GmbH \& Co. KG, Wiehl, Germany).

\subsection{Labelling and Data Base}

All extracts got an individual identification number which always started with the letters "EX" followed by a four-digit serial number. The identification number also included information about producer, solvent, and numbers of the extracts which are placed in the respective plate. These codes were noted in a central table which is available from the intra-net of our group. Every single extract was also entered in a web-based data-base accessible at www.epifood.de. Any details of a particular plant and the resulting extract, e.g. information about raw material, supplier of plant material, extraction process, extract producer, available amount etc. is retrievable there.

\section{Results and Discussion}

\subsection{Collection of Raw Material}

In order to collect a variety of different plants, we carried out the "take what is on offer" - principle which was encouraged by a discovery of a new plant species with anti-HIV activity while collecting a plant library (Thomas \& Gereau, 1993). We received 105 plants as extracts from three different professional suppliers. 63 different algae were prepared by CRM (Kiel, Germany) as extracts. 41 medical plant extracts were purchased as "tea-drug" from local pharmacies. The library contains extracts from more than $150 \mathrm{TCM}$ plants and 9 African plants. 140 plants were obtained by local outdoor cultivation. Nevertheless, most of the plant material $(>80 \%)$ was obtained from health shops or pharmacies; this included common plants such as stinging nettle, common valerian, or common dandelion. Overall, we collected 882 different plants classified into more than 190 botanical families. Figure 2 shows the representations of different plant families within PECKISH. Of note, the ancestry of a total of $69.1 \%$ of all plants belongs to diverse plant families ( $<1 \%$ of total extracts representative of a single family). $9.5 \%$ and $7.4 \%$ of the plants were from the Asteraceae and Lamiaceae family, respectively. Both, the Rosaceae as well as the Fabaceae family represent $5.6 \%$ of all plants. Due to broad diversity of plants, our library has a great potential of identifying the extracts desired effect.

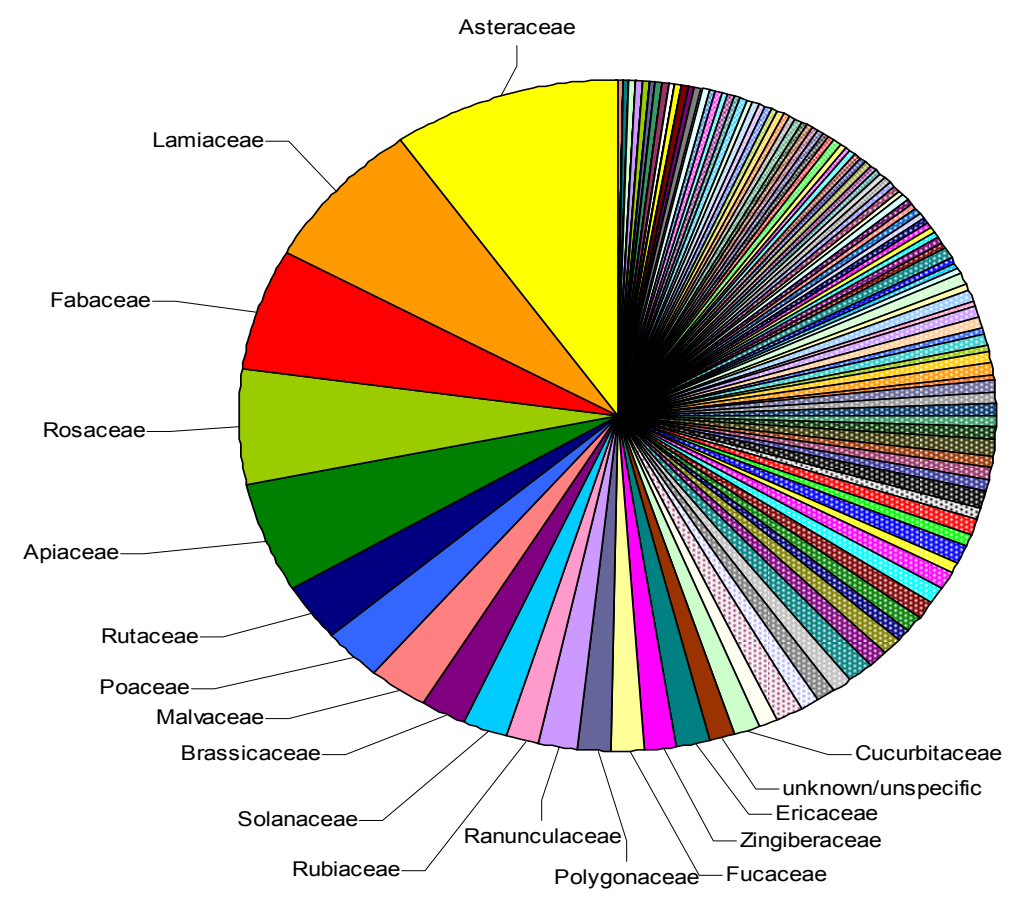

Figure 2. Variety of plant families within PECKISH 


\subsection{Plant tissues Used for Extraction}

In order to obtain extracts with diverse bioactive compounds and upon encouraging creation of the DTP library (McCloud, 2010), different parts of the collected plants were used for extraction (Table 1). About 16\% of the extracts come from roots or rootstocks, whereas approximately $9 \%$ of the extracts come from leaves and haulms, respectively. Blossoms (with and without calyx) and fruits (with parings, pits and peduncles) were extracted for about $7 \%$ of the extracts, respectively. Seeds $(6.2 \%)$ as well as bark (4.7\%) and thallus (4.3\%) were used for $15.2 \%$ of the extracts at large. Together, 11 different plant tissues were used for extractions.

Table 1. Different parts of the collected plants were used for extraction

\begin{tabular}{ll}
\hline Tissue & $\%$ of extracts \\
\hline Berries & 1,6 \\
Leaves & 9,4 \\
Blossoms (with and without calyx) & 7,5 \\
Fruits (with paring, pits \& peduncles) & 7,3 \\
Bark & 4,7 \\
Haulm & 9,0 \\
Rhizom & 1,0 \\
Seeds & 6,2 \\
Parings & 1,3 \\
Thallus & 4,3 \\
Roots/rootstocks & 15,8 \\
Others & 31,9 \\
\hline
\end{tabular}

\subsection{Solvents}

McCloud indicated that percolator extraction methods give similar results compared to simple extraction protocols (McCloud, 2010). Therefore, we developed three easy-to-handle extraction procedures allowing the preparation of over 4500 extracts within an adequate time. Thus, over $80 \%$ of plants in our collection was prepared as aqueous extract, ethanolic extract, or concentrated infusion. In our library, nearly two-thirds $(n=2884)$ of the extracts are aqueous and about $30 \%(\mathrm{n}=1442)$ were extracted by ethanol (Table 2$)$. There are only few extracts made with other solvents such as $\mathrm{CO}_{2}(\mathrm{n}=38 ; 0.8 \%)$, acetone $(\mathrm{n}=27 ; 0.6 \%)$, or DMSO $(\mathrm{n}=10 ; 0.2 \%)$. For $2.8 \%(\mathrm{n}=126)$ of the purchased extracts the solvents were unknown. Since plants contain a great variety of chemicals, there exist no single solvent able to solubilize all of them. Traditionally, the organic solvents (e.g. ethanol, methanol) are employed for extraction of biologically active agents from plants. Since over $90 \%$ of extracts in our library are aqueous or ethanolic, this may represent a substantial fraction of bioactive compounds.

Table 2. Solvents used for extraction and the percentage of the resulting extracts

\begin{tabular}{ll}
\hline Solvent & \% of extracts \\
\hline Acetone & 0.6 \\
Carbon dioxide $\left(\mathrm{CO}_{2}\right)$ & 0.8 \\
DMSO & 0.2 \\
Ethanol & 31.9 \\
Double distilled water & 63.7 \\
Unknown & 2.8 \\
\hline
\end{tabular}




\subsection{Format and Sterilization}

Since our library is dedicated to screening procedures, all plant extracts were aliquoted into 96 well-formats. Each plate contains six empty wells for positive and negative controls. Plates were sorted by solvent and producer, and were labelled individually. Due to the extracts' constitution, contamination problems in several bioassay trials are possible. Therefore, the whole library was sterilized via gamma-radiation.

\section{Conclusion}

Klausmeyer et al. found that plant specimen of about 20 years of age still contain biological active compounds (Klausmeyer et al., 2009). Using "stress-tests" (e.g. extract storage by higher temperatures) we found no changes regarding the major composition of selected extracts. However, we cannot exclude weak changes regarding fractions that are e.g. prone to oxidation but we assume that there are no substantial changes in general composition of the extracts. Nevertheless, we suggest that our library will be useful for the next 20 years as a long-term resource for screening of bioactive compounds. The 96-well library format allows medium throughput screenings using enzymatic assays, cell-based assays or phenotypic read-outs using model-organisms such as $C$. elegans or D. melanogaster. Because our Plant Extract Collection Kiel in Schleswig-Holstein (PECKISH) is an open access library we anticipate that our library will be used as a starting point to develop dietary supplements, functional foods or drugs.

\section{Acknowledgement}

We thank Maria Harms and Nina Freyse for production of plant extracts using the "tour de force" approach and Kevin Bernhard from CRM for extraction of the algae. This work was supported by the German Ministry of Education and Science (BMBF 01EA1317A). All authors have no conflict of interest.

\section{References}

Arai, S. (1996). Studies on functional foods in Japan-state of the art. Biosci Biotechnol Biochem, 60(1), 9-15. http://dx.doi.org/ 10.1271/bbb.60.9

Bindseil, K. U., Jakupovic, J., Wolf, D., Lavayre, J., Leboul, J., \& van der Pyl, D. (2001). Pure compound libraries; a new perspective for natural product based drug discovery. Drug Discov Today, 6(16), 840-847. http://dx.doi.org/10.1016/S1359-6446(01)01856-6,

Buehrer, B. M., Duffin, D. J., Lea-Currie, Y. R., Ribnicky, D., Raskin, I., Stephens, J. M., ... Gimble, J. M. (2012). Tools for the identification of bioactives impacting the metabolic syndrome: screening of a botanical extract library using subcutaneous and visceral human adipose-derived stem cell-based assays. J Nutr Biochem, 23(6), 519-525. http://dx.doi.org/ 10.1016/j.jnutbio.2011.02.005

de Morais Lima, G. R., de Albuquerque Montenegro, C., de Almeida, C. L., de Athayde-Filho, P. F., Barbosa-Filho, J. M., \& Batista, L. M. (2011). Database survey of anti-inflammatory plants in South america: a review. Int J Mol Sci, 12(4), 2692-2749. http://dx.doi.org/ 10.3390/ijms12042692

Eggenschwiler, J., Patrignani, A., Wagner, U., Rehrauer, H., Schlapbach, R., Rist, L., ... Viviani, A. (2006). Gene expression profiles of different breast cancer cells compared with their responsiveness to fermented mistletoe (Viscum album L.) extracts Iscador from oak (Quercus), pine (Pinus), white fir (Abies) and apple tree (Malus) in vitro. Arzneimittelforschung, 56(6A), 483-496. http://dx.doi.org/ 10.1055/s-0031-1296816

Eisenberg, D. M., Harris, E. S., Littlefield, B. A., Cao, S., Craycroft, J. A., Scholten, R., ... Clardy, J. (2011). Developing a library of authenticated Traditional Chinese Medicinal (TCM) plants for systematic biological evaluation--rationale, methods and preliminary results from a Sino-American collaboration. Fitoterapia, 82(1), 17-33. http://dx.doi.org/10.1016/j.fitote.2010.11.017

Gupta, R., Singhal, S., Goyle, A., \& Sharma, V. N. (2001). Antioxidant and hypocholesterolaemic effects of Terminalia arjuna tree-bark powder: a randomised placebo-controlled trial. J Assoc Physicians India, 49, 231-235.

Kahkonen, M. P., Hopia, A. I., Vuorela, H. J., Rauha, J. P., Pihlaja, K., Kujala, T. S., \& Heinonen, M. (1999). Antioxidant activity of plant extracts containing phenolic compounds. J Agric Food Chem, 47(10), 3954-3962. http://dx.doi.org/10.1021/j99901461

Khan, M. N., Choi, J. S., Lee, M. C., Kim, E., Nam, T. J., Fujii, H., \& Hong, Y. K. (2008). Anti-inflammatory activities of methanol extracts from various seaweed species. J Environ Biol, 29(4), 465-469. 
Kirk, H., Cefalu, W. T., Ribnicky, D., Liu, Z., \& Eilertsen, K. J. (2008). Botanicals as epigenetic modulators for mechanisms contributing to development of metabolic syndrome. Metabolism, 57(7 Suppl 1), S16-23. http://dx.doi.org/10.1016/j.metabol.2008.03.006

Klausmeyer, P., Zhou, Q., Scudiero, D. A., Uranchimeg, B., Melillo, G., Cardellina, J. H., ... McCloud, T. G. (2009). Cytotoxic and HIF-1alpha inhibitory compounds from Crossosoma bigelovii. J Nat Prod, 72(5), 805-812. http://dx.doi.org/10.1021/np8006342

Koch, E., \& Malek, F. A. (2011). Standardized extracts from hawthorn leaves and flowers in the treatment of cardiovascular disorders--preclinical and clinical studies. Planta Med, 77(11), 1123-1128. http://dx.doi.org/10.1055/s-0030-1270849

Liu, J., Burdette, J. E., Xu, H., Gu, C., van Breemen, R. B., Bhat, K. P., ... Bolton, J. L. (2001). Evaluation of estrogenic activity of plant extracts for the potential treatment of menopausal symptoms. J Agric Food Chem, 49(5), 2472-2479. http://dx.doi.org/10.1021/jf0014157

McCloud, T. G. (2010). High throughput extraction of plant, marine and fungal specimens for preservation of biologically active molecules. Molecules, 15(7), 4526-4563. http://dx.doi.org/10.3390/molecules 15074526

Pun, P. B., Gruber, J., Tang, S. Y., Schaffer, S., Ong, R. L., Fong, S., ... Halliwell, B. (2010). Ageing in nematodes: do antioxidants extend lifespan in Caenorhabditis elegans? Biogerontology, 11(1), 17-30. http://dx.doi.org/10.1007/s10522-009-9223-5

Subramaniam, S., Subramaniam, R., Rajapandian, S., Uthrapathi, S., Gnanamanickam, V. R., \& Dubey, G. P. (2011). Anti-Atherogenic Activity of Ethanolic Fraction of Terminalia arjuna Bark on Hypercholesterolemic Rabbits. Evid Based Complement Alternat Med, 2011, 487916. http://dx.doi.org/10.1093/ecam/neq003

Thomas, D. W., \& Gereau, R. E. (1993). Ancistrocladus korupensis (Ancistrocladaceae): A New Species of Liana from Cameroon. Novon, 3, 494-498. http://dx.doi.org/10.2307/3391401

Yang, Y., Seo, J. M., Nguyen, A., Pham, T. X., Park, H. J., Park, Y., ... Lee, J. (2011). Astaxanthin-rich extract from the green alga Haematococcus pluvialis lowers plasma lipid concentrations and enhances antioxidant defense in apolipoprotein E knockout mice. $J$ Nutr, 141(9), 1611-1617. http://dx.doi.org/10.3945/jn.111.142109

\section{Copyrights}

Copyright for this article is retained by the author(s), with first publication rights granted to the journal.

This is an open-access article distributed under the terms and conditions of the Creative Commons Attribution license (http://creativecommons.org/licenses/by/3.0/). 